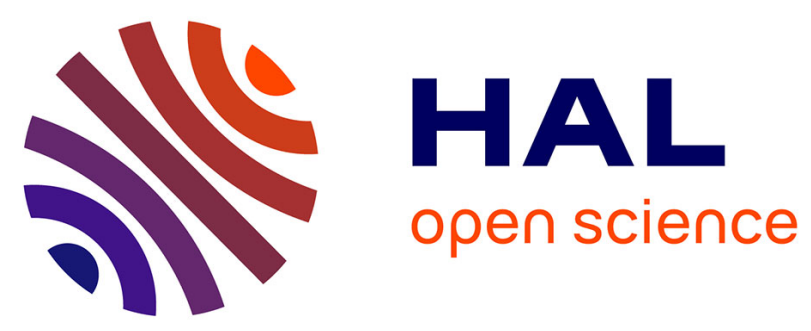

\title{
Passive coherent combining of two tapered laser diodes in an interferometric external cavity (poster)
}

Guillaume Schimmel, Ioana Doyen, S Janicot, Marc Hanna, Patrick Georges, Gaëlle Lucas-Leclin, J Decker, Paul Crump, Götz Erbert

\section{- To cite this version:}

Guillaume Schimmel, Ioana Doyen, S Janicot, Marc Hanna, Patrick Georges, et al.. Passive coherent combining of two tapered laser diodes in an interferometric external cavity (poster). High Power Laser Diode Conference, Oct 2015, Coventry, United Kingdom. 10.1109/HPD.2015.7439670 . hal01257023

\section{HAL Id: hal-01257023}

https://hal-iogs.archives-ouvertes.fr/hal-01257023

Submitted on 15 Jan 2016

HAL is a multi-disciplinary open access archive for the deposit and dissemination of scientific research documents, whether they are published or not. The documents may come from teaching and research institutions in France or abroad, or from public or private research centers.
L'archive ouverte pluridisciplinaire $\mathbf{H A L}$, est destinée au dépôt et à la diffusion de documents scientifiques de niveau recherche, publiés ou non, émanant des établissements d'enseignement et de recherche français ou étrangers, des laboratoires publics ou privés. 


\title{
Passive coherent combining of two tapered laser diodes in an interferometric external cavity
}

\author{
G. Schimmel ${ }^{1 *}$, I. Doyen, $\mathrm{S}^{1}$. Janicot ${ }^{1}$, M. Hanna ${ }^{1}$, P. Georges ${ }^{1}$, G. Lucas-Leclin ${ }^{1}$, \\ J. Decker ${ }^{2}$, P. Crump ${ }^{2}$, G. Erbert ${ }^{2}$ \\ ${ }^{1}$ Laboratoire Charles Fabry, UMR 8501, Institut d'Optique, CNRS, Univ Paris-Sud, 91127 Palaiseau, \\ France ("'guillaume.schimmel@institutoptique.fr), \\ ${ }^{2}$ Ferdinand-Braun-Institut, Leibniz-Institut für Höchstfrequenztechnik, Gustav-Kirchhoff-Straße 4, \\ 12489 Berlin, Germany
}

\begin{abstract}
We demonstrate a rear-side phase-locking architecture with two high-brightness diode lasers. This technique is based on the passive phase-locking of emitters in an external cavity on their rear facet, and their coherent combination on the front facet. Two high-brightness high-power tapered laser diodes are coherently combined using a Michelson-based cavity. The combining efficiency is above $80 \%$ and results in an output power of $6.5 \mathrm{~W}$ in a nearly diffraction-limited beam.
\end{abstract}

Index Terms-Coherent beam combining, external cavity, phase-locking, tapered diode laser.

\section{INTRODUCTION}

$\mathrm{C}$ oherent Beam Combining (CBC) consists in superposing several beams that are coherent with each other, thereby generating a single high-power laser beam with excellent spectral and spatial properties [1]. For CBC to be effective, the individual laser beams must have a proper phase relationship that remains constant over time. This can only be achieved in an arrangement that forces the required phase relation between the emitters. Over the years, different approaches have been investigated: active phase-locking of amplifiers seeded by a single-frequency laser split into $\mathrm{N}$ beams and amplified in parallel, or passive self-organization of emitters in a common laser cavity [2]. We investigate a new $\mathrm{CBC}$ architecture using a common laser external cavity on the back side of the emitters for phase locking, while coherent beam superposition of the phase-locked beams is realized on the front side. This technique leads to a separation of the phase-locking stage which takes place in the common external cavity on the rear side of the lasers - and the beam combining stage - which is achieved on the front side outside the cavity. As a consequence, the electrical-to-optical efficiency of the phaselocked laser array is increased as compared to standard external cavity configurations, since losses are minimized on the useful output [3]. We have already demonstrated this configuration with two low-power ridge lasers [4]. In this contribution, this technique is applied to high-brightness tapered devices demonstrating the potential of extended-cavity phase-locking arrangements for high-power operation.

\section{High-POWER PASSIVE CBC ARCHITECTURE}

\section{A. High-brightness tapered laser diodes}

For this experiment, we used tapered laser devices emitting around $\lambda=976 \mathrm{~nm}$. Details of the device design are given in [5], in this case without any internal gratings and with the rear facet anti-reflection coated. The tapered lasers were mounted p-side up on C-Mount (instead of CCP) to allow access to both facets, which limits how effectively they can be cooled. The lasers contain a $2 \mathrm{~mm}$ long ridge section, and a $4 \mathrm{~mm}$ long tapered section $\left(6^{\circ}\right.$ taper angle). The two sections are separately driven by currents $I_{R}$ and $I_{T}$, respectively. After external stabilization, the extracted optical power reaches $4 \mathrm{~W}$ at $\mathrm{I}_{\mathrm{R}}=400 \mathrm{~mA}$ and $\mathrm{I}_{\mathrm{T}}=6 \mathrm{~A}$, corresponding to an electrical-tooptical (E-O) efficiency of $26 \%$. The beam is diffractionlimited along the fast axis; along the slow axis the beam quality factor is $\mathrm{M}_{4 \sigma}^{2} \approx 2.5$ at $\mathrm{I}_{\mathrm{T}}=6 \mathrm{~A}$ - with about $80 \%$ of the extracted power contained in the diffraction-limited central lobe. For such lasers, separate (rear side) phase-locking and (front side) coherent combining is the preferred and most promising configuration, as optical feedback into the front facet (tapered-section) is expected to deteriorate the beam quality, and may even lead to early device failure.

\section{B. Experimental set-up}

The external cavity is based on a Michelson interferometer on the rear-side: the two laser beams are combined on a 50/50 beamsplitter $\left(\mathrm{BS}_{1}\right)$, and a diffraction grating at Littrow incidence on one arm closes the external cavity (Figure 1). Since both lasers share the same external cavity, they undergo minimum losses if the two laser beams are in phase at the $\mathrm{BS}_{1}$ - resulting in constructive interference on the $\mathrm{P}$ arm, and

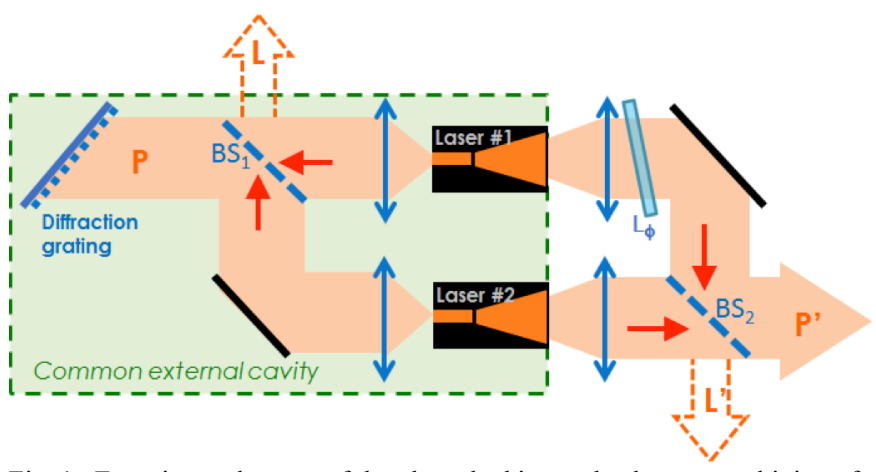

Fig. 1. Experimental set-up of the phase-locking and coherent combining of two lasers; BS: 50/50 beamsplitter; L, L’: losses; $\mathrm{L}_{\Phi}$ : static phase adjustment. 
destructive interference on the other arm. This external cavity forces phase-locked operation of the tapered lasers. On their front facet, a simple $50 / 50$ beamsplitter $\left(\mathrm{BS}_{2}\right)$ is used as a combiner to perform coherent superposition of the beams. A phase plate $\mathrm{L}_{\Phi}$ - an anti-reflection coated plane silica plate - is added on one arm to adjust the phase relationship between the two laser beams. Rotating the plate allows fine tuning of the phase difference, and maximizing the combined power in the $\mathrm{P}^{\prime}$ arm. The maximum combined optical power at the $\mathrm{P}^{\prime}$ output of the front interferometer is $6.5 \mathrm{~W}$ at $\mathrm{I}_{\mathrm{T}}=6 \mathrm{~A}$ and $\mathrm{I}_{\mathrm{R}}=$ $400 \mathrm{~mA}$, corresponding to a combining efficiency defined as the ratio of the combined power $\mathrm{P}^{\prime}$ on the total power $\left(\mathrm{L}^{\prime}+\mathrm{P}^{\prime}\right)$ $\eta_{\mathrm{P}}^{\prime},=82 \%$; the E-O efficiency $\eta_{\mathrm{E}-\mathrm{O}}$ is thus $\geq 21 \%$.

\section{Optimization of the coherent combination efficiency}

It is noteworthy that the combining efficiency $\eta_{\text {P' }}^{\prime}$, evaluated here is actually limited by the beam imperfections, as the tapered laser diodes are not perfectly single transverse mode. Actually we observe that the external cavity on the rear side acts as a lateral mode filter: the beam quality is improved to $\mathrm{M}^{2}{ }_{4 \sigma} \leq 1.3$ when the two emitters are phase-locked at $\mathrm{I}_{\mathrm{T}}=6 \mathrm{~A}$. And since the combining stage on the front facets operates as a second spatial filter, the beam quality of the combined beam is enhanced to $\mathrm{M}_{4 \sigma}^{2} \leq 1.2$ (Figure 2). Indeed, only the common features in the spatial intensity and phase of both beams are coherently combined. This results in a spatial cleaning effect on the combined beam, whereby lateral modes are rejected on the loss arm. Finally we implement an additional spatial filtering stage on the combined beam to select only the central diffraction-limited lobe from each of the beams. The measured combining efficiency is $92 \%$, corresponding to a maximum combined power of $5.9 \mathrm{~W}$ in the filtered beam (Figure 3 ). This experimental combining efficiency agrees with its theoretical estimation based on the experimental beam intensity and phase profiles [7].

Under phase-locked operation, the laser line corresponds to a true single-frequency operation of both lasers in the external cavity. Nevertheless perturbations of the laser cavity result in mode-hops of the laser frequency, which are associated with fast jumps of the phase relationship between the two laser beams on the front side. To ensure long-term stability, a semiactive feedback loop is implemented on the ridge-section currents of both devices, which is based on a random exploration algorithm: the power $\mathrm{L}^{\prime}$ on the front side is measured at a $10 \mathrm{~Hz}$ rate, and the currents are automatically changed to minimize the L' power if needed. Then the two lasers remain phase-locked and their phase relationship on the front side is maintained such as the output power $\mathrm{P}^{\prime}$ remains at its maximum.

\section{CONCLUSION}

To conclude, we have shown that the rear-side architecture can be applied to high power tapered laser diodes, making it a promising technique to scale the brightness of laser diode systems. The combined power achieved with only two lasers is comparable to the state-of-the-art in a self-organized resonator with ten emitters [6], while maintaining a high E-O efficiency. Further investigations will focus on the extension to a larger number of emitters.

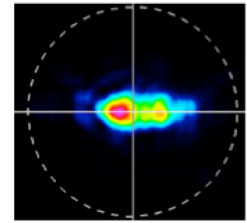

Incoherent operation $M^{2} \leq \mathbf{2 . 5}$

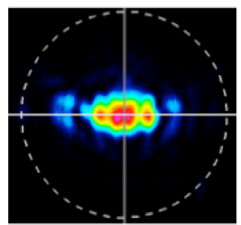

Phase-locked $M^{2} \leq 1.3$

Fig. 2. Front-side collimated beam profiles of laser \#1 under incoherent (top) and phase-locked operation (bottom) at operating currents $I_{R}=400 \mathrm{~mA}$ and $\mathrm{I}_{\mathrm{T}}=6 \mathrm{~A}$.

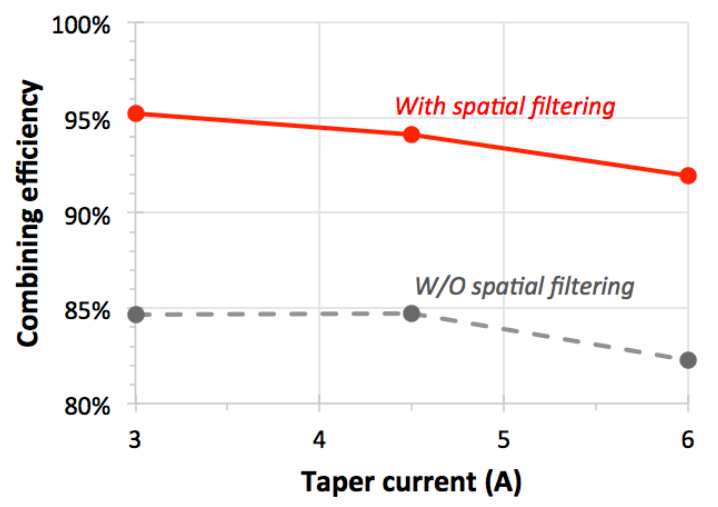

Fig. 3. Combining efficiency measured on the front side of the tapered lasers, with and without spatial filtering of the laser beams.

\section{ACKNOWLEDGMENT}

This work was supported in part by the European Commission within the BRIDLE program $\left(7^{\text {th }} \mathrm{FP}\right)$ under Grant 314719. We thank Gunnar Blume and Katrin Paschke from the FBH for detailed technical discussions and for providing the tapered laser devices used in this investigation.

\section{REFERENCES}

[1] Fan, T.Y, "Laser beam combining for high-power, high-radiance sources", IEEE J. of Sel. Top. in Quant. Electr. 11 (3), 567-577 (2005)

[2] Coherent Laser beam combining, A. Brignon, ed, Wiley - VCH (2013)

[3] Montoya, J et al., "External cavity beam combining of 21 semiconductor lasers using SPGD", App. Opt. 51(11), 1724-1728 (2012)

[4] G. Schimmel et al, "Separate phase-locking and coherent combining of two laser diodes in a Michelson cavity", in Proc. SPIE 9348, HighPower Diode Laser Technology and Applications XIII, 93480P (April 1, 2015); doi:10.1117/12.2079314

[5] Fiebig, C et al, "12W high-brightness single-frequency DBR tapered diode laser" Electron. Lett 44 (21), 1253-1255 (2008).

[6] Huang, Robin K. et al. "Coherent combination of slab-coupled optical waveguide lasers." in Novel In-Plane Semiconductor Lasers VIII. Ed. A. A. Belyanin \& P. M. Smowton. Proc. SPIE, vol.7230, 72301G (2009).

[7] Goodno, G. D. et al, "Perturbative analysis of coherent combining efficiency with mismatched lasers" Opt. Expr. 18 (24), 25403-254014 (2010) 